\title{
Pineal and Adrenal Effects on Calcium Homeostasis in the Rat
}

\author{
DAVID O. HAKANSON AND WILLIAM H. BERGSTROM
}

Department of Pediatrics, SUNY Health Science Center, Syracuse, New York 13210

\begin{abstract}
In human infants and newborn rats, white light at the intensity used to treat hyperbilirubinemia lowers serum calcium concentration. Occipital shielding or (in newborn rats) exogenous melatonin prevents this effect. Propranolol, by inhibiting melatonin synthesis, also causes hypocalcemia, which is preventable by melatonin. Metyrapone or adrenalectomy prevents hypocalcemia after light exposure or propranolol. Exogenous corticosterone lowers serum calcium; this is prevented by supplementary melatonin. In adult rats, the change in calcium after light, propranolol, or corticosterone is minimal. After parathyroidectomy or a diet with a high calcium/low phosphorus ratio, the hypocalcemic effect of these three agents is restored. Bone samples removed after light exposure or corticosterone administration show increased calcium uptake; this is blocked by supplementary melatonin in vivo or by addition of melatonin to the incubation medium. We postulated that the hypocalcemic effect of light or propranolol was due to an acute increase in corticosterone-mediated bone calcium uptake when circulating melatonin was decreased by reduction of the rate of melatonin synthesis. In our study, pinealectomized rats showed no change in serum calcium after light or propranolol; their hypocalcemic response to corticosterone was greater than that of shamoperated controls. Exogenous parathyroid hormone prevented light-induced hypocalcemia in newborn rats. (Pediatr Res 27: 571-573, 1990)
\end{abstract}

\section{Abbreviations}

\author{
$A R$, adult rats $>100 \mathrm{~g}$ \\ NBR, newborn rats, 7-14 g \\ Pnx, pinealectomized \\ Rach, rachitogenic
}

When human infants (1) and NBR (2) are exposed to white light at the intensity used in phototherapy for jaundice, serum calcium concentration decreases by $0.175-0.225 \mathrm{mmol} / \mathrm{L}$. This can be prevented or reversed by shielding the occiput, but not by using blindfolds (2). In NBR, the hypocalcemic response is accompanied by a decrease in serum melatonin and an increase in serum corticosterone. When exogenous melatonin is given or when endogenous synthesis is sustained by isoproterenol (3) during light exposure, serum calcium does not change (4). Propranolol, which inhibits pineal melatonin synthesis (3), lowers serum calcium in shaded NBR unless exogenous melatonin is provided (4).

Corticosterone administration lowers serum calcium concen-

Received October 10, 1989; accepted January 29, 1990.

Correspondence and reprint requests: David O. Hakanson, M.D., Department of Pediatrics, Division of Neonatology, SUNY Health Science Center at Syracuse, 750 E. Adams Street, Syracuse, NY 13210. tration in NBR; this effect is prevented by simultaneous melatonin administration (2). When corticosterone synthesis is inhibited by metyrapone, serum calcium does not fall during light exposure $(2,4)$. Previous studies (5) have shown an acute increase in bone calcium uptake after corticosterone administration in vivo or addition of the steroid to bone incubation medium in vitro; in both situations, melatonin blocks the effect of corticosterone on bone calcium uptake.

From these findings, we derive the hypothesis that hypocalcemia during phototherapy or propranolol administration results from a corticosterone-mediated shift of calcium from interstitial fluid into bone when photic or pharmacologic inhibition of melatonin synthesis causes a fall in plasma melatonin concentration (4). If this hypothesis is valid, Pnx rats should show no change in serum calcium concentration after light exposure or propranolol administration, and their hypocalcemic response to exogenous corticosterone should be greater than that of shamoperated controls. Also, metyrapone should minimize the change in serum calcium after propranolol; conversely, propranolol should enhance the hypocalcemic response to corticosterone. Our study was designed to investigate these possibilities.

Because pinealectomy was not feasible in NBR, it was necessary to use animals weighing approximately $100 \mathrm{~g}$ ( $2 \mathrm{wk}$ past weaning). In intact rats of this size, the change in serum calcium after light exposure, propranolol, and corticosterone was much less than that found in NBR. We postulated that enhanced parathyroid function after weaning to standard rat food might confer resistance to hypocalcemia. We therefore compared the effect of all three agents on serum calcium concentration in NBR, in AR on rat food, and in AR on a high calcium/low phosphorus diet, a regimen known to produce functional hypoparathyroidism (6). We also compared the serum calcium response to light in NBR given exogenous parathyroid hormone with that found in vehicle-injected controls. Because susceptibility to hypocalcemia was restored in AR by the high calcium/low phosphorus diet, we used this regimen to compare responses to light, propranolol, and corticosterone in Pnx rats and in shamoperated controls.

\section{MATERIALS AND METHODS}

Intact and Pnx male Sprague-Dawley rats (the latter with sham-operated controls) were obtained from Taconic Farms, Germantown, NY. For 2 wk, the groups indicated below were given a high-calcium/low phosphorus ration [Rach test diet (United States Biochemical Corp, Cleveland, $\mathrm{OH}$ ); calcium, $1.2 \%$; phosphorus, $0.2 \%$ ]. Controls were kept on standard rat food (calcium, $1.2 \%$, phosphorus, $0.8 \%$ ). Adrenalectomies were done under chloral hydrate anesthesia; operated animals were supplied with half-normal saline overnight before use. The light stimulus, delivered under chloral hydrate anesthesia, consisted of a 1-min-exposure to a white fluorescent light source (Westinghouse F40T12 bulbs, Westinghouse Electric Corporation, Bloomfield, NJ) at a lamp-cranium distance of $1 \mathrm{~cm}$. This procedure delivered $3 \mathrm{~J}$ light energy $/ \mathrm{cm}^{2}$ at the surface of the 
scalp. Controls were held for $1 \mathrm{~min}$ at the same distance from the light source with an opaque shield interposed. In NBR, an equivalent amount of photic energy was delivered by exposure to light for $1 \mathrm{~h}$ at a distance of $8 \mathrm{~cm}$; controls were kept in shaded boxes for the same interval. Tail blood samples were obtained immediately before and $1 \mathrm{~h}$ after light exposure in adults; in NBR, blood samples were secured by decapitation. Plasma calcium was measured by titration using fluorescein as an indicator (7).

Propranolol (as Inderal, Ayerst Laboratories, New York, NY), metyrapone (as Metopirone, Ciba Pharmaceutical Co., Summit, NJ), melatonin (Sigma Chemical Co., St. Louis, MO), and corticosterone (in $0.2 \%$ ethanol in normal saline) were given by intraperitoneal injection. Parathyroid hormone (as bovine fragment 1-34, Sigma) was given intramuscularly. Tail blood plasma calcium was measured $1.5 \mathrm{~h}$ after corticosterone and $2 \mathrm{~h}$ after propranolol. Controls received the appropriate vehicle.

\section{RESULTS}

Table 1 shows the effects of light, propranolol, and corticosterone on serum calcium concentration in NBR and AR whose adrenal, parathyroid, and pineal status was modified by surgical, dietary, or pharmacologic means. In the NBR, all three agents lowered serum calcium concentration.

In shaded rats, serum melatonin concentration was $650 \pm 120$ $\mathrm{pmol} / \mathrm{L}$; after $3 \mathrm{~h}$ of light exposure, it was $270 \pm 78 \mathrm{pmol} / \mathrm{L} ; n$ $=23+23, p<0.01$. Intraperitoneal melatonin at $90 \mathrm{nmol} / \mathrm{kg}$ gave a serum concentration of $25.8 \mathrm{nmol} / \mathrm{L}$ at $10 \mathrm{~min}$; this declined exponentially, reaching $1722 \mathrm{pmol} / \mathrm{L}$ at $1 \mathrm{~h}$ and 345 $\mathrm{pmol} / \mathrm{L}$ at $2 \mathrm{~h} \mathrm{(4).}$

Exogenous melatonin prevented hypocalcemia after light and corticosterone and lessened the response to propranolol. Metyrapone prevented hypocalcemia after light exposure and also blocked the effect of propranolol. When parathyroid hormone was given immediately before light exposure, serum calcium concentration did not change significantly.

In $\mathrm{AR}$ on laboratory food (calcium, $1.2 \%$; phosphorus, $0.8 \%$ ), the change in serum calcium after light, propranolol, and corti- costerone was less than in NBR; the rach diet (calcium, 1.2\%; phosphorus, $0.2 \%$ ) restored the response to light and corticosterone. Adrenalectomy-parathyroidectomy also increased the calcium response to corticosterone. When melatonin was given together with corticosterone in adult adrenalectomized-parathyroidectomized rats, the calcium response was blocked as it has been in the NBR.

Pnx rats on the rach diet showed no hypocalcemic response to light or to propranolol. Their response to corticosterone at 0.23 $\mu \mathrm{mol} / \mathrm{kg}$ was greater than that of sham-operated controls.

Figure 1 illustrates the interaction between corticosterone and propranolol. At and below $0.14 \mu \mathrm{mol} / \mathrm{kg}$, corticosterone did not evoke hypocalcemia; when given with $0.39 \mu \mathrm{mol} / \mathrm{kg}$ of propranolol, $0.14 \mu \mathrm{mol} / \mathrm{K}$ was as effective as $0.58 \mu \mathrm{mol} / \mathrm{kg}$ alone. Propranolol alone at this dose was ineffective.

\section{DISCUSSION}

The effects of pinealectomy on serum calcium changes after light, propranolol, and corticosterone indicate that melatonin is involved in calcium homeostasis, as proposed in the hypothesis above. Light or propranolol sufficient to lower serum melatonin concentration leads to a decrease in serum calcium in intact rats (4); this effect was not found after pinealectomy. The hypocalcemic effect of exogenous corticosterone is associated with an increase in bone calcium uptake; both the decrease in serum calcium and the increase in bone calcium uptake are prevented by melatonin administration (5). The dose of corticosterone needed to evoke hypocalcemia is decreased by pinealectomy and by propranolol.

These findings suggest that melatonin affects calcium homeostasis by preventing the enhancement of bone calcium uptake by corticosterone. The mechanism responsible for this interaction is presently obscure, in part because the means by which cortisol (or corticosterone) influences bone calcium uptake is not known. The concept that melatonin may block the effect of a steroid hormone on one of its end-organs is not novel. Inhibition of the actions of exogenous testosterone on the seminal vesicles and prostate has been demonstrated in castrated rats $(8,9)$.

Table 1. Change in serum calcium concentration*

\begin{tabular}{|c|c|c|c|c|c|c|}
\hline \multirow[b]{2}{*}{ Subjects } & \multicolumn{2}{|r|}{$\begin{array}{l}\text { Light } \\
\left(3 \mathrm{~J} / \mathrm{cm}^{2}\right)\end{array}$} & \multicolumn{2}{|c|}{$\begin{array}{c}\text { Propranolol } \\
(9.7 \mu \mathrm{mol} / \mathrm{kg})\end{array}$} & \multicolumn{2}{|c|}{$\begin{array}{l}\text { Corticosterone } \\
(0.58 \mu \mathrm{mol} / \mathrm{kg})\end{array}$} \\
\hline & $n$ & $\begin{array}{c}\mathrm{Ca} \\
(\mathrm{mmol} / \mathrm{L})\end{array}$ & $n$ & $\begin{array}{c}\mathrm{Ca} \\
(\mathrm{mmol} / \mathrm{L}) \\
\end{array}$ & $n$ & $\begin{array}{c}\mathrm{Ca} \\
(\mathrm{mmol} / \mathrm{L})\end{array}$ \\
\hline NBR & 61 & $-0.200(0.012) \dagger$ & 11 & $-0.400(0.040) \S$ & 10 & $-0.175(0.017) \S$ \\
\hline $\begin{array}{l}\text { NBR + melatonin } \\
\quad(2 \mu \mathrm{g} / \mathrm{g})\end{array}$ & 38 & $-0.025(0.015) \mathrm{NS}$ & 10 & $-0.200(0.042) \|$ & 15 & $0.0(0.020)$ \\
\hline $\begin{array}{l}\text { NBR + metyrapone } \\
\quad(25 \mu \mathrm{g} / \mathrm{g})\end{array}$ & 17 & $-0.044(0.019) \mathrm{NS}$ & 7 & $0.0(0.035)$ & & \\
\hline NBR, ADX & 5 & $-0.0(0.037) \mathrm{NS}$ & & & & \\
\hline $\mathrm{NBR}+\mathrm{PTH}$ & 12 & $-0.025(0.025) \mathrm{NS}$ & & & & \\
\hline $\begin{array}{l}\text { AR, standard rat food } \\
\text { diet }\end{array}$ & 10 & $-0.100(0.025) \|$ & 10 & $-0.125(0.030) \|$ & 8 & $-0.050(0.015)$ \\
\hline$A R$, rach diet & 10 & $-0.300(0.015) \neq$ & & & 6 & $-0.200(0.030) \ddagger$ \\
\hline $\mathrm{AR}, \mathrm{ADX} / \mathrm{PTX}$ & & & & & 9 & $-0.150(0.020) \S$ \\
\hline \multirow[t]{2}{*}{$\begin{array}{l}\text { AR, ADX/PTX + } \\
\text { melatonin }(2 \mu \mathrm{g} / \mathrm{g})\end{array}$} & & & & & 7 & $0.0(0.030) \mathrm{NS}$ \\
\hline & & & & & & $(0.23 \mu \mathrm{mol} / \mathrm{kg})$ \\
\hline$A R, P n x$, rach diet & 12 & $-0.075(0.037) \mathrm{NS}$ & 8 & $-0.025(0.050) \mathrm{NS}$ & 12 & $-0.225(0.017) \S$ \\
\hline AR, Sham rach diet & 10 & $-0.250(0.025)$ & 8 & $-0.025(0.067) \S$ & 10 & $-0.025(0.030) \mathrm{NS}$ \\
\hline
\end{tabular}

* ADX, adrenalectomized; PTH, parathyroid hormone; PTX, parathyroidectomized. Values in parentheses represent SE.

$\dagger p<0.01$ vs shaded controls.

$\ddagger p<0.01$ vs standard rat food diet response.

$\S p<0.01$ vs vehicle-injected controls.

$\| p<0.01$ vs NBR. 


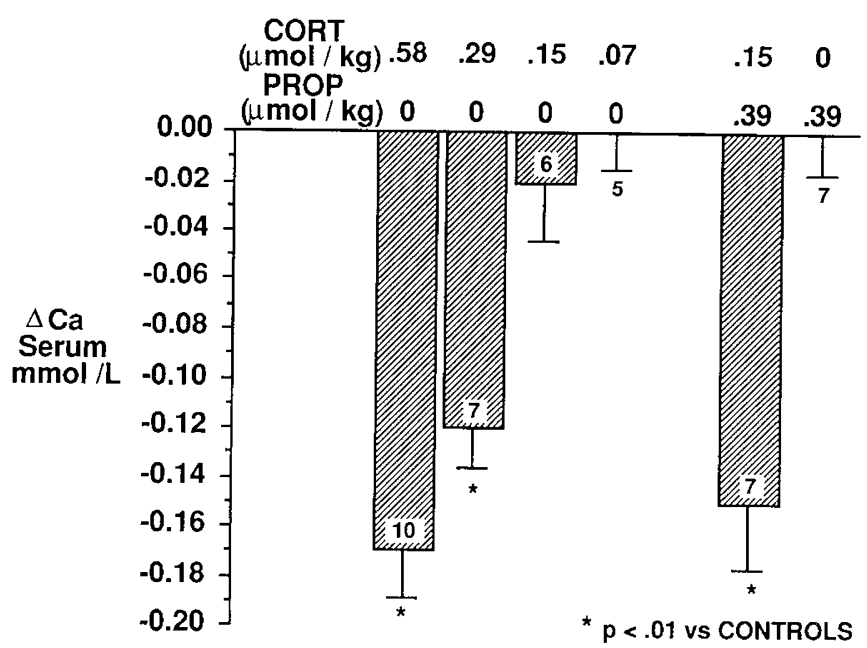

Fig. 1. Changes in serum calcium concentration $1.5 \mathrm{~h}$ after intraperitoneal injection of corticosterone and propranolol alone or in combination.

In rats of the sizes used in these experiments, intraperitoneal cortisol at $0.55 \mu \mathrm{mol} / \mathrm{kg}$ gives serum cortisol concentrations of $0.64 \pm 0.17 \mu \mathrm{mol} / \mathrm{L}$ at $10 \mathrm{~min}$ and $0.44 \pm 0.06 \mu \mathrm{mol} / \mathrm{L}$ at $6 \mathrm{~h}$; stressed human infants have cortisol levels of $0.61-0.72 \mu \mathrm{mol} / \mathrm{L}$ compared to $0.14-0.19 \mu \mathrm{mol} / \mathrm{L}$ in controls $(10)$. The data cited and discussed above refer to the hypocalcemic effect of corticosterone, the predominant glucocorticoid in rodents. Cortisol, predominant in man, has the same hypocalcemic effect in NBR (change after corticosterone, $0.175 \mathrm{mmol} / \mathrm{L}$; after cortisol, 0.200 $\mathrm{mmol} / \mathrm{L}, \mathrm{SE}=+0.017, n=10 / 10)$. Hypocalcemia is common in stressed human neonates (11). In intact $\mathrm{AR}$, corticosterone has little effect on serum calcium concentration; either parathyroidectomy or a high calcium/low phosphorus diet restores the hypocalcemic response to corticosterone. Similar effects of cortisol on serum calcium have been reported in human subjects with hypoparathyroidism $(12,13)$.

In persons with normal parathyroid function, as in intact adult rats, the melatonin-cortisol interaction probably has no significant effect on calcium homeostasis.

\section{REFERENCES}

1. Romagnoli C, Polidore G, Cataldi L, Tortorolo G, Segni G 1979 Phototherapyinduced hypocalcemia. J Pediatr 94:815-816

2. Hakanson DO, Bergstrom WH 1981 Phototherapy-induced hypocalcemia in newborn rats: prevention by melatonin. Science 214:807-809

3. Deguchi T, Axelrod J 1973 Control of circadian change of serotonin $N$ acetyltransferase activity in the pineal organ by the $\beta$-adrenergic receptor. Proc Natl Acad Sci USA 69:2547-2550

4. Hakanson DO, Penny R, Bergstrom WH 1987 Calcemic responses to photic and pharmacologic manipulation of serum melatonin. Pediatr Res 22:414416

5. Hakanson DO, Bergstrom WH 1982 Prevention of light-induced hypocalcemia by melatonin. In: Norman AW, Schaefer K, Herrath DV, Grigoleit H-G (eds) Vitamin D: Chemical, Biochemical and Clinical Endocrinology of Calcium Metabolism. Walter de Gruyter, New York, pp 1163-1165

6. Rogers MC, Bergstrom WH 1971 Diet-induced hypoparathyroidism: a model for neonatal tetany. Pediatrics 47:207-210

7. Bett JM, Fraser GP 1959 A rapid micro method for determining serum calcium. Clin Chim Acta 4:346-356

8. Debeljuk L, Feder VM, Paulucci OA 1970 Effects of melatonin on changes induced by castration and testosterone in sexual structures of male rats. Endocrinology 87:1358-1360

9. Alonso R, Prieto L, Hernandez C, Mas M 1978 Antiandrogenic effects of the pineal gland and melatonin in castrated and intact prepubertal male rats. $J$ Endocrinol 79:77-83

10. Bergstrom WH, Williams ML, Jacobs RD, Nervez CT, Gottuso MA 1980 Acute effects of adrenal and ovarian steroids on calcium metabolism. In DeLuca H, Anast CS (eds) Pediatric Diseases Related to Calcium. Elsevier, New York, pp 217-218

11. David L, Anast CS 1974 Calcium metabolism in newborn infants. J Clin Invest 54:287-296

12. Forbes GB 1956 Clinical studies of idiopathic hypoparathyroidism in children. Ann NY Acad Sci 64:432-455

13. Farrell PM, Rikkers H, Moel D 1976 Cortisol-dihydrotachysterol metabolism in a patient with hypoparathyroidism and adrenal insufficiency: apparent inhibition of bone resorption. J Clin Endocrinol Metab 42:953-957 